\title{
B-RAF V600E AND B-RAF CODON 464-469 MUTATIONS IN HAIRY CELL LEUKEMIA PATIENTS AND THEIR RELATION WITH CLINICAL PARAMETERS
}

\author{
Aybuke OLGUN 1 , Yasemin BASBINAR ${ }^{2}$, Inci ALACACIOGLU ${ }^{3}$, Serife \\ SOLMAZ ${ }^{4}$, Mahdi AKBARPOUR ${ }^{5}$, Tugba UYSAL KILIC ${ }^{6}$, Ozlem BIRGE ${ }^{7}$, \\ Sermin OZKAL ${ }^{8}$, Hulya ELLIDOKUZ ${ }^{9}$, Mehmet Ali OZCAN ${ }^{3}$
}

\footnotetext{
${ }^{1}$ Health Scinces University, Izmir Tepecik Research and Training Hospital, Department of Hematology, Izmir, TURKEY

2 Dokuz Eylül University, Institute of Oncology, Department of Translational Oncology, Izmir, TURKEY

${ }^{3}$ Dokuz Eylül University, School of Medicine, Department of Hematology, Izmir, TURKEY

${ }^{4}$ Izmir Katip Celebi University, Ataturk Training and Research Hospital, Department of Hematology, Izmir, TURKEY

${ }^{5}$ German Cancer Consortium (DKTK), Clinical Cooperation Unit Translational Radiation Oncology, German Cancer Research Center(DKFZ), Department of Radiation Oncology, Heidelberg University Hospital(UKHD), National Center for Tumor Diseases(NCT) Heidelberg Institute of Radiation Oncology(HIRO), Heidelberg, Germany, Heidelberg lon-Beam Therapy Center(HIT)

${ }^{6}$ Hitit University, Faculty of Science and Art, Department of Molecular Biology and Genetics, Corum, TURKEY

${ }^{7}$ Health Scinces University, Antalya Research and Training Hospital, Department of Pathology, Antalya, TURKEY

${ }^{8}$ Dokuz Eylül University, School of Medicine, Department of Pathology Izmir, TURKEY

${ }^{9}$ Dokuz Eylül University School of Medicine, Department of Biostatistics Izmir, TURKEY
}

Address for Correspondence: Aybuke OLGUN, E-mail: aybukeh.olgun@gmail.com Received: 07.02.2021; Accepted: 13.09.2021; Available Online Date: 20.09.2021

@C Copyright 2021 by Dokuz Eylül University, Institute of Health Sciences - Available online at https://dergipark.org.tr/en/pub/jbachs Cite this article as: Olgun A, Basbinar Y, Alacacioglu I, Solmaz S, Akbarpour M, Uysal-Kilic T, Birge O, Ozkal S, Ellidokuz H, Ozcan MA. B-Raf V600e and B-Raf Codon 464-469 Mutations in Hairy Cell Leukemia Patients and Their Relation With Clinical Parameters. J Basic Clin Health Sci 2021; 3: 1-6.

\begin{abstract}
Purpose: Hairy cell leukemia (HCL) is a chronic lymphoproliferative disorder which counts \%2-3 percent of the leukemias. B-RAF is a member of mitogen activated protein kinase pathway, associated with cell proliferation. The most common B-RAF mutation V600E has been shown in hairy cell leukemia recently. The aim of our study is to investigate B-RAF V600E and B-RAF codon 464-469 mutations in HCL patients and compare the results with clinical parameters.

Methods: Thirteen individuals who were diagnosed and followed up with hairy cell leukemia in Dokuz Eylul University Faculty of Medicine Hematology outpatient clinic are included in our study. Demographic and clinical data are collected and B-RAF mutations are analyzed with pyrosequencing based molecular methods.

Results: B-RAFV600E mutation was positive in $10(\% 76,9)$ patients. B-RAF G464E was mutated in one patient, BRAF G466E was positive in another and B-RAF G469E mutation has been found in a patient. Two patients had both codon 600 and codon 464-469 mutations, showing no invincible difference clinically. All the patients having lymphadenopathy had B-RAFV600E mutations $(p=1.000)$. Response rates were similar in the groups having $B-$ RAFV600E mutation and/or B-RAF codon 464-469 mutations.

Conclusions: B-RAF is a commonly mutated gene in hairy cell leukemia with different types of muatations. Especially B-RAFV600E mutation can be used as a supportive diagnostic test, in cases with contraversial diagnosis or differential diagnosis of other peripheral B cell neoplasms. Also it can be used as a marker to select the candidate patients for target therapies, who did not respond to the conventional therapies.

Keywords: Hairy cell leukemia, B-RAF V600E, B-RAF G464E, B-RAF G469E
\end{abstract}




\section{INTRODUCTION}

Hairy cell leukemia $(\mathrm{HCL})$ is a $B$ cell lymphoproliferative disorder, presenting with spleen, liver and bone marrow infiltration; which was first described as Leukemic Reticuloendothelosis in 1958 (1). Later on, Schrek and Donnely named the disease "Hairy cell leukemia", because of the mononuclear cells with irregular cytoplasmic projections observed in the blood and marrow (2). HCL accounts for \%4,5 of non-Hodgkin lymphomas, more commonly seen in man (3). Most of the patients present with fatigue, infectious complications, abdominal pain due to cytopenias and splenomegaly. Diagnosis is based on the examination of peripheral blood smear, flow cytometry and the bone marrow aspiration-biopsy $(4,5)$. HCL is highly responsive to purine analogs if diagnosed correctly $(6,7)$.

Recently, Tiacci et al. demonstrated B-RAFV600E mutation in \%100 of their HCL cases (8). B-RAF (rapidly accelerated fibrosarcoma) is a proteinserine/threonine kinase; which is a member of MAPK (mitogen activated protein kinase) pathway that regulates cell growth, differentiation and proliferation (9). The most common B-RAF mutation; BRAFV600E occurs as a result of substitution of the valin by glutamate in codon 600 . The mutation causes constitutive activation of MAPK pathway (10). Later on; Tschernitz et al. reported two rare B-RAF mutations in exon 11(F468C and D449E) of two BRAFV600E negative HCL patients (11).

Aim of our study is to investigate the frequency of BRAFV600E mutation and other rare mutations of $B$ RAF in exon 11 (B-RAFG464E, B-RAFG466E, BRAFG469V) and their relation with clinical data and treatment responses.

\section{MATERIAL AND METHODS}

Charts of 13 patients diagnosed with $\mathrm{HCL}$ were retrospectively analyzed. Patients' age, gender, sypmtoms at the time of diagnosis, secondary malignancies, hematologic paremeters were evaluated. For all patients the diagnosis was confirmed morphologically and immunhistochemically. HCL variant type patients were excluded. All patients were hospitalized and treated with one cycle of cladribine; $0,1 \mathrm{mg} / \mathrm{kg} /$ day intravenous infusion for 7 days. One patient received subcutanous IFNa at a dose of 4,5 mIU/day for eleven days prior to cladribine therapy. Complete response criteria are defined as the disapperance of HCL cells in peripheral blood and bone marrow, normalization of blood count (absolute neutrophil count $=$ ANC $>1500 / 10^{9} \mathrm{l}$, hemoglobin $=\mathrm{Hb} \quad>12 \mathrm{gr} / \mathrm{dl}$ and platelets $=P \mid t>150000 / 10^{9} \mathrm{l}$ and resolving of organomegaly and lympadenopathy by physical and radiolographic examination. Partial response is defined as normalization of cytopenias along with a minimum \%50 improvement in organ involvment and bone marrow and the absence of hairy cells in peripheral blood. Responses are evaluated according to posttreatment results at 4 or 6 months (12).

Spleen and bone marrow tissue samples were obtained from paraffin-embedded blocks archived at the Department of Pathology, Dokuz Eylul University Faculty of Medicine. Tissue samples were prepared 10 micron slides. Molecular analyzes were performed in the laboratory of Molecular Oncology. DNA was isolated from paraffin-embedded tumor tissue with a spin column-based commercial DNA extraction kit (QIAamp DNA FFPE Tissue Kit; Qiagen, Germany) according to the manufacturer's instructions. Quantification of the amount of extracted DNA by spectrophotometry. BRAF mutations were determined with pyrosequencing method (Qiagen PyroMark Q24 system, Therascreen BRAF Pyrokit 24, V1 (1/2) kit) Mutation and clinical data analysis was conducted using the SPSS 15.0 software. (IBM, NY, USA) Minimum, median and maximum values of numerical variables are summarized and analyzed with Mann Whitney $U$ test. Percent distributions of categorical variables are summarized and analyzed with chi-squared test. $p<0,05$ was accepted as statistically significant. The study was approved by the local ethics board of Dokuz Eylul University.

\section{RESULTS}

\section{Patient demographics}

Nine of the patients were male, four patients were female. Median age at diagnosis was 48 (37-59). Median follow-up was 59 (3-96) months.

\section{Clinical Findings}

At the time of diagnosis, $\% 46,2(n=6)$ of patients were asymptomatic. Fatigue, left upper quadrant pain, weight loss, dyspnea were the symptoms at diagnosis and two patients were hospitalized for hemorrhagic diarrhea and neutropenic fever. All of the patients had splenomegaly $(n=13)$, five patients had hepatomegaly and two had intraabdominal lymhadenopathy. Approximately half of the patients $(\% 46,2)$ diagnosed with splenectomy; none of the 
other patients had splenectomy for treatment or palliation. Only one patient was pancytopenic at diagnosis. Four patients were anemic $(\mathrm{Hb}<10 \mathrm{gr} / \mathrm{dL})$, six were thrombocytopenic (Plt<150000/109). Leucopenia was $\% 84,6(n=11)$, four of these patients were also neutropenic (ANC<1500/10 9 ). Monocytopenia commonly seen in $\mathrm{HCL}$ was detected $\% 61,5(n=8)$ among our patients. One of the patients was diagnosed with Mantle cell lymphoma (MCL) and treated a year ago and in remission for both MCL and $\mathrm{HCL}$; one was diagnosed Kaposi carcoma just before the diagnosis of HCL and lost in follow-up. None of the patients had autoimmune disease.

\section{Treatment and Responses}

Eleven patients were treated with cladribine $0,1 \mathrm{mg} / \mathrm{kg} /$ day continously infusion; for 7 days. One patient was treated with interferon- $\alpha$ at a dose of $4,5 \mathrm{mIU} /$ day, for 11 days due to neutropenic fever and pneumoniae; then continued the same cladribine regimen as the others. One patient was asymptomatic with mild cytopenias $(\mathrm{Hb}>10 \mathrm{gr} / \mathrm{dL}$, PIt $>100000 / 10^{9} \mathrm{I}, \quad$ ANC>1000/10 9 I) and followed without treament for a year. At the time of study this patient was on cladribine treatment for detoriation of treatment response. None of other patients relapsed or died in follow-up. We couldn't perform survival analysis because all the patients were CR at the time of study with no relapse or death.

\section{B-RAF Mutation Analysis Results}

B-RAFV600E - common mutation of BRAF in $\mathrm{HCL}$ was detected in $10(\% 76,9)$ of our patients. Rare mutations of B-RAF codon 464-469 in exon 11 were detected in 3 patients (one patient with B-RAFG464E, one patient with B-RAFG466E, one patient with BRAFG469E mutation) Two patients were positive for both mutations and showed no significant clinical differences compared to other patients. B-RAF mutation rates (common and rare) were similar in both men and women. All patients with lymphadenopathy were positive for B-RAFV600E mutation but there was no statistical significance. $(p=1.000)$ As a remarkable finding, B-RAFV600E was mutated in all patients with normal thrombocyte count; whereas the mutation was positive in $\% 50$ of the thrombocytopenic patients. $(p=0,70)$ Nine out of ten patients with B-RAFV600E mutation were leucopenic. The patients which have B-RAF 464-469 codon mutations were all leucopenic and

Table 1. Mutation analysis results of our cases

\begin{tabular}{|c|c|c|c|c|c|}
\hline PATIENT & TISSUE & $\begin{array}{l}\text { CODON } \\
600\end{array}$ & $\begin{array}{l}\text { MUTATION } \\
\text { TYPE }\end{array}$ & $\begin{array}{l}\text { CODON 464- } \\
469\end{array}$ & $\begin{array}{l}\text { MUTATION } \\
\text { TYPE }\end{array}$ \\
\hline Patient 1 & Spleen & Mutant & $1799 \mathrm{~T}>\mathrm{A}$ & Mutant & $1397 \mathrm{G}>\mathrm{A}$ \\
\hline Patient 2 & Spleen & Mutant & $1799 \mathrm{~T}>\mathrm{A}$ & Wild & Wild \\
\hline Patient 3 & Spleen & Mutant & $1799 \mathrm{~T}>\mathrm{A}$ & Wild & Wild \\
\hline Patient 4 & Spleen & Mutant & $1799 \mathrm{~T}>\mathrm{A}$ & Wild & Wild \\
\hline Patient 5 & Spleen & Mutant & $1799 \mathrm{~T}>\mathrm{A}$ & Wild & Wild \\
\hline Patient 6 & Spleen & Mutant & $1799 \mathrm{~T}>\mathrm{A}$ & Wild & Wild \\
\hline Patient 7 & Bone marrow & Mutant & $1799 \mathrm{~T}>\mathrm{A}$ & Wild & Wild \\
\hline Patient 8 & Bone marrow & Mutant & $1799 \mathrm{~T}>\mathrm{A}$ & Wild & Wild \\
\hline Patient 9 & Bone marrow & Mutant & $1799 \mathrm{~T}>\mathrm{A}$ & Wild & Wild \\
\hline Patient 10 & Bone marrow & Wild & Wild & Mutant & $1406 \mathrm{G}>\mathrm{T}$ \\
\hline Patient 11 & Bone marrow & Mutant & $1799 \mathrm{~T}>\mathrm{A}$ & Mutant & $1391 \mathrm{G}>A$ \\
\hline Patient 12 & Bone marrow & Wild & Wild & Wild & Wild \\
\hline Patient 13 & Bone marrow & Wild & Wild & Wild & Wild \\
\hline
\end{tabular}

hematologic parameters. Eleven patients were eligible for the evaluation of response with CR at all. 2 patients were lost in follow-up; one with CR at 62th month, and one at third month without evaluation of lymphopenic. There was no statistical significance in relationships between the hematologic parameters and mutations. Treatment responses were similar in 
groups with B-RAFV600E and/or B-RAF 464-469 codon mutations.

\section{DISCUSSION}

$\mathrm{HCL}$ is most commonly seen among men and at middle age. In our study demographic data was consistent with the literature (1). Approximately half of the HCL patients are symptomatic at diagnosis with the symptoms due to cytopenias or splenomegaly. Infections, splenomegaly, hepatomegaly, lymphadenopathy findings were observed at similar rates reported in other studies $(4,5,13)$. Pancytopenia was rarer, and the difference may arise from the early diagnosis of patients investigated due to splenomegaly. Dearden et al. reported that, the disease free survival of $\mathrm{HCL}$ patients recieving pentostatin or cladribine therapy is better if $\mathrm{Hb}>10 \mathrm{gr} / \mathrm{dL}$ and/or platelet $>100000 / \mathrm{dL}$. (14). In our cohort, no relaps or death occured in follow-up so the relationship of these parameteres couldn't be analyzed. HCL patients may develop non-Hodgkin lymphomas, chronic myeloproliferative diseases, leukemias, solid organ cancers (lung, prostate, colon), melanom or other skin cancers before the diagnosis or after the treatment $(15,16)$. One patient was treated for Mantle cell lymphoma before $\mathrm{HCL}$ diagnosis and one patient had concurrent Kaposi carcoma disease with $\mathrm{HCL}$ diagnosis, none of the other patients developed secondary malignancies in follow-up. Many researchers investigated the long term effects of first line therapy on secondary malignancies with purine analogues. Goodman et al. investigated the long term effects of cladribine treatment of $209 \mathrm{HCL}$ patients and reported an approximately 2 fold increase in secondary malignancies; the risk was related with previous cancer history and age (15). Else et al. assessed the long term effects of pantostatin and cladribine therapies and the secondary malignancy incidence was similar with normal population at same age and gender (7). Secondary malignancy incidence was reported similar with the normal population after pentostatin or IFNa treatments in other studies $(17,18)$. As a result, we can suggest that there is no clear evidence for development of secondary malignancies related to $\mathrm{HCL}$ treatment.

Cladribine was preferred for all patients who received treatment, depending on the experience of the center and the availability of the drug. There is no randomised controlled trial comparing cladribine and pentostain. The data of treatment responses and side effects are obtained from large case series $(14,17,19,20)$. Else et al. showed no significant difference between the responses of pentostatin and cladribine therapies in a group of $233 \mathrm{HCL}$ patients (7). Similar results of pentostatin and cladribine were reported by Dearden et al. and randomised controlled studies comparing these agents were suggested to obtain real data (14). In our patients, whom were eligible for response evaluation, complete response rate with cladribine was $\% 100$; similar with the literature $(21,22)$. Treatment response was reported as the most significant factor affecting disease free survival (7). None of our patients were relapsed and this result may be associated with treatment outcome as well as the short median follow-up time.

B-RAFV600E mutation was reported up to $\% 100$ of HCL patients using different molecular methods such as Sanger sequencing, allele-specific PCR, highresolution melting analysis (8,23-25). Ten of our patients $(\% 76,9)$ were positive for B-RAFV600E mutation. Similar rates were reported by Shao et al. (\%76) and $\mathrm{Xi}$ et al. (\%79) using the same pyrosequencing based molecular method as our study $(26,27)$. But there are also other studies reporting $\% 100$ B-RAFV600E mutation positivity with pyrosequencing method. Thus, the lower rate in our patient group was thought to be independent of molecular method, but may be associated about the genetic and geographic differences or the small number of study group $(28,29)$. Therefore a multicenter study with a larger patient group may reveal the real data for Turkey.

As mentioned before, $\% 15,4$ of our patients had lymphadenopathy as a rare clinical finding, and all these three patients were positive for mutation. Such comparison about lymphadenopathy and mutation wasn't done in studies where all patients were positive for B-RAFV600E mutation (8,23-25,28-30). Also this clinical finding wasn't evaluated in studies which our mutation rates were similar $(26,27)$. We think that there may be a clinical association, but this prediction should be verified in larger patient group.

As a result of our literature and Catalogue of Somatic Mutations in Cancers (COSMIC) Database research, we found out that B-RAF codon 464-469 in exon 11 mutations were not identified in HCL patients before (31). Three of our patients $(\% 27,1)$ had these mutations and this may be related to ethnic factors, but also may be mutations that have not been reported in $\mathrm{HCL}$ patients before. 


\section{Study Limitations}

Hairy cell leukemia is an uncommon lyphomproliferative disorder. Small number of our patient group and the high responsive nature of the disease resulted in a lack of statistical assesment.

\section{CONCLUSION}

B-RAF is a frequently and variably mutated gene in hairy cell leukemia. In particular, B-RAFV600E mutation can be used as a supportive genetic test in cases with contraversial diagnosis or differential diagnosis of other peripheral B cell neoplasms. It may also be an important biomarker in selection of the cases where the targeted therapies will be applied.

Author contribution: The project was constructed by A.O., Y.B., and M.A.O. Y.B., A.O. M.A, T.U.K., S.O. and O.B. designed and performed experiments. A.O., Y.B., and H.E. analysed the data. A.O., I.A. and S.S. were responsible for data collection and processing. A.O., Y.B., S.S., I.A, S.O. and H.E. wrote the manuscript, and M.A.O edited the manuscript.

Conflict of interests: Authors declare no conflict of interest.

Funding: None.

Peer-review: Externally peer-reviewed.

\section{REFERENCES}

1. Bouroncle BA, Wiseman BK, Doan CA. Leukemic Reticuloendotheliosis. Blood. 1958;13(7):609-30.

2. Schrek R, Donnelly WJ. "Hairy" cells in blood in lymphoreticular neoplastic disease and "flagellated" cells of normal lymph nodes. Blood. 1966; 27(2): 99-211.

3. Morton LM, Sampson JN, Cerhan JR, Turner JJ, Vajdic CM, Wang SS, et al. Rationale and Design of the International Lymphoma Epidemiology Consortium (InterLymph) NonHodgkin Lymphoma Subtypes Project. JNCI Monogr 2014; 2014(48): 1-14.

4. Hoffman $M$ a. Clinical Presentations and Complications of Hairy Cell Leukemia. Hematol Oncol Clin North Am 2006; 20(5): 1065-73.

5. Kraut E. Clinical manifestations and infectious complications of hairy-cell leukaemia. Best Pract Res Clin Haematol 2003; 16(1): 33-40.

6. Else M, Ruchlemer R, Osuji N, Del Giudice I, Matutes E, Woodman A, et al. Long remissions in hairy cell leukemia with purine analogs: a report of 219 patients with a median follow-up of 12.5 years. Cancer 2005; 104(11): 2442-8.
7. Else M, Dearden CE, Matutes E, GarciaTalavera J, Rohatiner AZS, Johnson S a N, et al. Long-term follow-up of 233 patients with hairy cell leukaemia, treated initially with pentostatin or cladribine, at a median of 16 years from diagnosis. Br J Haematol. 2009; 145(6): 733-40.

8. Tiacci E, Trifonov V, Ph D, Schiavoni G, Holmes $A$, Kern $W$, et al. Braf mutations in hairy cell leukemia. N Engl J Med 2011; 364(24): 230515.

9. Roskoski R. RAF protein-serine/threonine kinases: Structure and regulation. Biochem Biophys Res Commun. 2010; 399(3): 313-7.

10. Cantwell-Dorris E, O'Leary J, Sheils O. BRAFV600E: Implications for carcinogenesis and molecular therapy. Mol Cancer Ther. 2011; 10(3): 385-94.

11. Tschernitz $S$, Flossbach $L$, Bonengel $M$, Roth $S$, Rosenwald A, Geissinger E. Alternative BRAF mutations in BRAF V600E-negative hairy cell leukaemias. Br J Haematol. 2014;165(4):529533.

12. Jones G, Parry-Jones N, Wilkins B, Else M, Catovsky D. Revised guidelines for the diagnosis and management of hairy cell leukaemia and hairy cell leukaemia variant. $\mathrm{Br} \mathrm{J}$ Haematol 2012; 156(2): 186-95.

13. Polliack A. Hairy cell leukemia: Biology, clinical diagnosis, unusual manifestations and associated disorders. Rev Clin Exp Hematol 2002; 6(4): 366-88.

14. Dearden C, Else M, Catovsky D. Long-term results for pentostatin and cladribine treatment of hairy cell leukemia. Leuk Lymphoma 2011; 52(Sup 2): 21-4.

15. Goodman GR. Extended Follow-Up of Patients With Hairy Cell Leukemia After Treatment With Cladribine. J Clin Oncol 2003; 21(5): 891-6.

16. Flinn IW, Kopecky KJ, Foucar MK, Head D, Bennett JM, Hutchison R, et al. Long-term follow-up of remission duration, mortality, and second malignancies in hairy cell leukemia patients treated with pentostatin. Blood 2000; 96(9): 2981-6.

17. Maloisel F, Benboubker L, Gardembas M, Coiffier B, Divine M, Sebban C, et al. Long-term outcome with pentostatin treatment in hairy cell leukemia patients. A French retrospective study of 238 patients. Leukemia 2003; 17(1): 45-51.

18. Federico M, Zinzani PL, Frassoldati A, Vinceti M, Modè A, Annino L, et al. Risk of second cancer 
in patients with hairy cell leukemia: long-term follow-up. J Clin Oncol 2002; 20(3): 638-646.

19. Golomb HM. Hairy cell leukemia: treatment successes in the past 25 years. J Clin Oncol 2008; 26(16): 2607-9.

20. Grever MR, Zinzani PL. Long-term follow-up studies in hairy cell leukemia. Leuk Lymphoma 2009; 50(Supl 1): 23-6.

21. Goodman GR, Burian C, Koziol J a, Saven A. Extended follow-up of patients with hairy cell leukemia after treatment with cladribine. J Clin Oncol 2003; 21(5): 891-6.

22. Jehn $U$, Bartl $R$, Dietzfelbinger $H$, Haferlach $T$, Heinemann V. An update: 12-year follow-up of patients with hairy cell leukemia following treatment with 2-chlorodeoxyadenosine. Leukemia 2004; 18(9): 1476-81.

23. Boyd EM, Bench AJ, van 't Veer MB, Wright $P$, Bloxham DM, Follows $G$ a, et al. High resolution melting analysis for detection of BRAF exon 15 mutations in hairy cell leukaemia and other lymphoid malignancies. $\mathrm{Br} \mathrm{J}$ Haematol 2011; 155(5): 609-12.

24. Tiacci E, Schiavoni G, Forconi F, Santi A, Trentin $\mathrm{L}$, Ambrosetti $\mathrm{A}$, et al. Simple genetic diagnosis of hairy cell leukemia by sensitive detection of the BRAF -V600E mutation. Blood 2012; 119(1): 192-5.

25. Langabeer SE, O'Brien D, Liptrot S, Flynn CM, Hayden PJ, Conneally E, et al. Correlation of the BRAF V600E mutation in hairy cell leukaemia with morphology, cytochemistry and immunophenotype. Int J Lab Hematol 2012; 34(4): 417-21.

26. Xi L, Arons E, Navarro W, Calvo KR, StetlerStevenson M, Raffeld M, et al. Both variant and IGHV4-34-expressing hairy cell leukemia lack the BRAF V600E mutation. Blood. 2012; 119: 3330-2.

27. Shao H, Calvo KR, Grönborg M, Tembhare PR, Kreitman RJ, Stetler-Stevenson $M$, et al. Distinguishing hairy cell leukemia variant from hairy cell leukemia: Development and validation of diagnostic criteria. Leuk Res 2013; 37(4): 401-9.

28. Laurini J a, Aoun P, Iqbal J, Chan W, Greiner TC. Investigation of the BRAF V600E mutation by pyrosequencing in lymphoproliferative disorders. Am J Clin Pathol 2012; 138(6): 87783.
29. Verma S, Greaves WO, Ravandi F, Reddy N, Bueso-Ramos CE, O'Brien S, et al. Rapid detection and quantitation of BRAF mutations in hairy cell leukemia using a sensitive pyrosequencing assay. Am J Clin Pathol 2012; 138(1): 153-6.

30. Tiacci E, Schiavoni G, Martelli MP, Boveri E, Pacini R, Tabarrini A, et al. Constant activation of the RAF-MEK-ERK pathway as a diagnostic and therapeutic target in hairy cell leukemia. Haematologica 2013; 98(4): 635-9.

31. Catalogue of Somatic Mutations in Cancer [Internet]. Available from: http://cancer.sanger.ac.uk/cancergenome/proje cts/cosmic/ 